\title{
Analysis and New Approaches to the Solution of Problems of Operation of Oil and Gas Complex as Cyber-Physical System
}

\author{
Tahmasib Kh. Fataliyev * and Shakir A. Mehdiyev \\ Institute of Information Technology of ANAS, Baku, Azerbaijan \\ E-mail:*tfataliyev@gmail.com, \{depart3,depart11\}@iit.science.az
}

Received: 31 August 2018; Accepted: 24 September 2018; Published: 08 November 2018

\begin{abstract}
The application of modern information technologies in the oil and gas sector is constantly developing, which facilitates the acceleration of exploration and detection of oil, the increase in oil production and reduction in risks relates to health, human safety, and the environment. The Internet of things in the oil and gas sector, like in all sectors of industry, has great prospects from an economic point of view. The article is devoted to the study of the current state and avenues of solving key problems of effective and reliable functioning of the oil and gas industry as a cyber-physical system using the Internet of things in the Azerbaijani oil company SOCAR. The main technological processes and existing opportunities for the application of information technologies in the oil and gas complex are analyzed. New approaches are proposed to solve the problems in the oil and gas complex as cyber-physical system based on the smart sensors, the Internet of things, wireless networks and cloud technologies. The implementation of the proposed model is aimed at increasing the effectiveness, resource storage, exploration reliability and durability of the oil and gas complex.
\end{abstract}

Index Terms-Oil and gas complex, Internet of Things, Industry 4.0, cyber-physical systems, maintenance.

\section{INTRODUCTION}

Currently, despite the active search for alternative energy sources, oil and natural gas remain the most important energy carriers, and petroleum products are the main type of fuel and components for the production of several important materials and substances. They are also the largest sources of greenhouse gas emissions, and the potential impact on water systems is a growing concern as well. These trends have led the oil and gas complex (OGC) companies to engage in exploration, drilling, extraction, processing and delivery of raw materials extracted from the bowels of the earth and the sale of final products of those and encounter numerous technical, economic and environmental problems, the solution of which requires the minimization financial expenditure and cost reduction; the optimization of work on the entire fund of exploited wells; minimizing environmental risks and a responsible approach to the health and safety of personnel.

In order to address the emerging problems, studies have been conducted on the use of measuring instruments for automatic control of oil production processes and the introduction of accident-preventing alarms starting from the mid-20th century. As a result of this research, positive expert assessments have been made regarding the prospects of the introduction of automation and remote control systems (various primary converters, local devices, etc.) for the monitoring and control of oil and gas production facilities. These systems would solve a limited number of tasks regarding object-related data exchange between communication devices and database maintenance, perform data processing in real time, display information on the monitor screen in a convenient and understandable manner for the operator form and solve some tasks for emergency and warning alarming.

The dispersal of technological objects of OGC in large areas required solving the problem of the economic expediency of development and implementation of telemechanical systems, organizational structures of remote control and system management of complex technological objects and processes.

Main obstacles to the realization of given ideas could be:

- Immature information and communication infrastructure.

- The limited capacity of primary measuring equipment (devices).

- Insufficient computing power and storage capacity.

- Limited data transmission capabilities.

The lack of openness of software tools and formats for data exchange left a special imprint on the nature of technical and organizational solutions in the automation of oil and gas production enterprises. This process was of a local nature, each enterprise or unit within one enterprise used its own (private) management system, which was incompatible with other systems.

However, the incremental development of ICT, the emergence and accessibility of the Internet, as well as 
functionally new primary information sensors created certain technical capabilities when the management of physical objects began to be carried out directly through the Internet. In particular, the Internet of things (IoT), stable communication channels, cloud technologies and digital platforms, as well as a multiple increases in data flows ensured the appearance of open information systems and interacting industrial networks beyond the boundaries of individual enterprises. Such systems and networks had a major impact on the translation of automation systems to the level of the fourth industrial revolution (the term was introduced in 2011 under the German initiative - Industry 4.0). The definition of Industry 4.0 is diverse, as it is still at the stage of research and development [1-3]. However, we should agree with the authors $[4,5]$ who highlight the technical essence of Industry 4.0 as the integration of cyber-physical systems (CPS), IoT and services into industrial processes, including production and logistics. Другими словами, CPS implies the integration of the real world of physical objects into the virtual world of computing processes (embedded computers, network, and cloud technologies) via globally connected IoT. IoT is an important a paradigm in connection with the CPS, as it emphasizes the use of existing technologies and architectures for large-scale systems for the identification and virtualization of physical devices [6,7]. The concept of IoT refers to the connection of uniquely identifiable devices in the Internet infrastructure using various technologies such as RFID, ZigBee, Bluetooth or 6LoWPAN and includes physical objects in the World Wide Web, which allows you to create an application layer for physical objects.

Thus, it can be concluded that the integrated automation of technological processes in oil and gas industry can be performed within the framework of CPS and is one of the priority areas of the development of Industry 4.0.

\section{PROBLEM DEFINITION}

OGC has a number of features, which include a variety of technological processes; technological danger of these processes; territorial distribution; the continuous nature of hydro and gas dynamic processes; the presence of systems of oil and gas supply that are unique for their scale and complexity, etc. Traditionally, automated control and management systems are used to solve these problems. Their structure includes a large number of devices for various purposes. When reviewing the OGC as a CPS, there is a mutual integration of separate control systems into a single information space, in the formation of which the following information technology achievements play an essential role:

- Evolution of mini, micro and nano-sensor production technologies with the ability to collect various information (temperature, pressure, vibration, distance, position, angle of rotation, chemical composition of the substance, etc.) from the control and management facilities;

- Transition to IPv6 technology, which removes restrictions on the number of sensors and devices that are connected;

- Introduction of wireless communication technologies that enable to directly extract information from sensors installed in the real measurement zone of parameters of various technological processes;

- Development and improvement of cloud, fog, dew structures that help to store large volumes of information and enable the application of complex analytical tools such as Big Data, Data Mining, OLAP, Pattern Recognition, etc.

The purpose of this work is to study the current state of the art and the ways to solve the key problems of effective and reliable functioning of OGC processes aimed at:

- Establishment of a "smart" OGC;

- The efficiency of control, management and prevention;

- Automatic execution of resource-intensive forecasts;

- Improvement of technological processes for exploration, drilling and exploitation of oil and gas fields;

- Monitoring of the state of oil and gas wells and mining equipment, effective operation and preventive maintenance, remote monitoring of hazardous production and valuable equipment;

- Increase the productivity of both processes and staff;

- Reduction of energy consumption;

- Reduction of unpredictable shutdowns and the number of maintenance and repair work;

- Elimination of work requiring personnel to stay in production zones that are hazardous to health and life;

- Reducing environmental risks and increasing safety, etc.

\section{BRIEF DESCRIPTION AND ANALYSIS OF TECHNOLOGICAL PROCESSES IN OGC}

Technological processes in OGC structure is carried out in a sequential manner in three sectors, which are commonly referred to as Upstream, Midstream, and Downstream (Fig. 1):

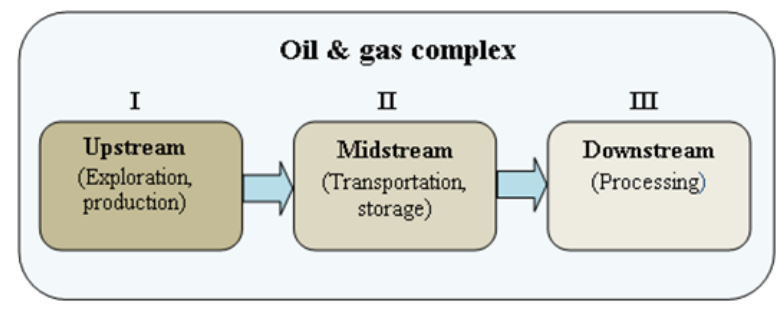

Fig.1. Block-scheme of technological processes in OGC. 
The Upstream sector comprises the stages of the search of potential deposits of hydrocarbons (oil and natural gas), exploratory drilling and raw material quarrying, that is, the extraction of oil or natural gas from onshore platforms or offshore from the bowel of the earth.

In the Midstream sector, the extracted oil with impurities passes through local pipelines and pumped into primary reservoirs-batteries where oil is separated from gas and water. Thereafter, the crude oil is stored in reservoirs-storage tanks, from where it travels through oil trunk pipelines to oil refineries, to other storage tanks, tanker vessels or tank wagons for transportation. Pumping stations are installed for pumping oil through pipelines at regular intervals along the entire length of the route. Pumps are used to initiate and maintain pressure, overcome friction, account for the difference in altitude along the length of the route and other factors.

In the Downstream sector, oil or natural gas is processed to produce final products such as gasoline, kerosene, jet fuel, diesel fuel, fuel oil, lubricating oils, liquefied gas, plastics and other materials.

Several studies are devoted to monitoring and control systems in various sectors of the OGC in the literature. Some of them are listed below.

\section{A. Drilling}

A systematic approach to the process of automation of the drilling process was proposed in [9]. Based on the borehole and surface data obtained in real time, the calculated practical models are compared with theoretical models. Given the changing circumstances, such a system changes the operating parameters settings, for example, the pump flow, hook weight or the drill string rotation speed. The example of a drilling rig in Fig. 2 shows the use of various sensors for measuring these parameters [9].

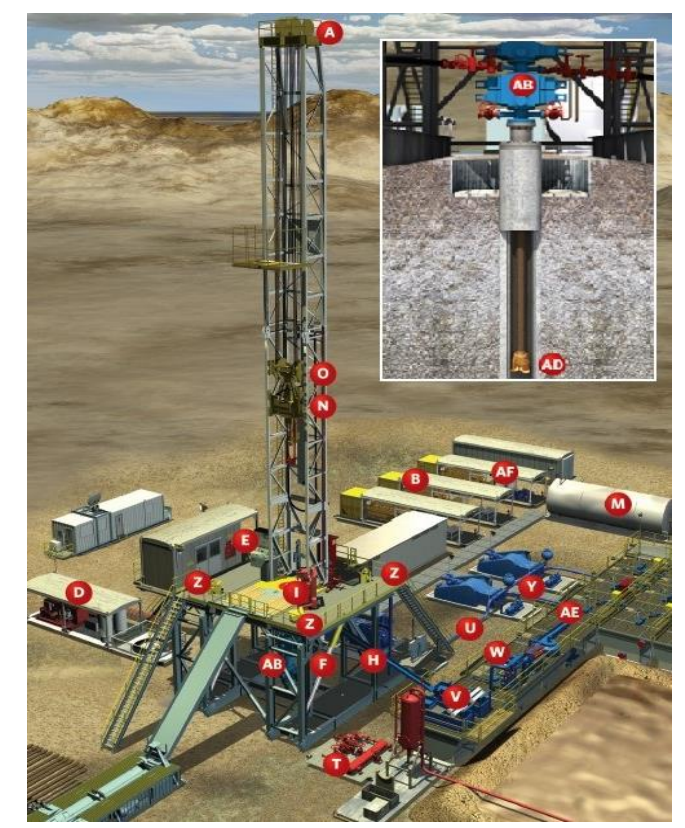

Fig.2. Placement of measuring zones and sensors on drilling rig.
Let's list some of them (letters indicate the locations of sensors):

- Measurement of the weight through the tension of the cable along the drilling line $(\mathrm{A}),(\mathrm{N}),(\mathrm{O})$;

- Measurement of oil, water and hydraulic fluid pressure (B);

- $\quad$ Torque monitoring $(\mathrm{H}),(\mathrm{I}),(\mathrm{N})$;

- Measurement of drilling mud pressure and flow control (U);

- Measurement of direct and indirect loads (Z);

- Measurement of liquid level in tanks (M), (AF);

- Measurement of pressure or pressure drop at high temperatures and pressure ranges in the drilling bit region $(\mathrm{AD})$;

- Control and monitoring of breakthroughs, uncontrolled releases of crude oil and/or natural gas from the well (AB).

Appropriate decisions are made having knowledge of the current process and controlling the main parameters of the drilling process.

\section{B. Transportation}

One of the main problems of OGC is the transportation and delivery of oil, gas, and derivatives to consumers. Oil and gas pipelines can be several thousand kilometers long (for example, the length of the Redwater-Port-Credit oil pipeline in Canada is $4,840 \mathrm{~km}$, the length of the BakuTbilisi-Ceyhan oil pipeline is 1,768 km), pass through hard-to-reach and sparsely populated areas and pose a great environmental hazard due to the threat of leaks and spills of hydrocarbon raw materials in case of accidents and other emergencies. This can also occur due to corrosion/erosion phenomena [10]. Corrosion is a serious problem, both on offshore and on offshore oil and gas grounds, hence, the need to diagnose it and measure the destruction of the materials used (Fig. 3).

In some cases, corrosion can be easily determined by visual monitoring (VM). VM is the simplest, however, at the same time, the most time- and labor-consuming method. In order to conduct the VM of the pipeline, the insulation layer must be completely removed. Detected spots of corrosion are measured with the sensors or digitized with a 3D scanner, which helps to determine the area and depth of defects as accurately as possible. Thereafter, a decision is made on the necessity to replace or repair a defective pipe section. After the control is complete, the insulation surveillance and leak detectionoriented sensors can perform online spectral analysis to identify the relevant is restored and the object is restarted.

It is possible to use small unmanned aerial vehicles (drones) to supplement conventional approaches to monitoring the oil and gas pipeline [11]. Here, too, is given a comparative table of the various sensors used for this purpose. Smaller drones equipped with video surveillance and leak detection-oriented sensors can perform online spectral analysis to identify the relevant information. 


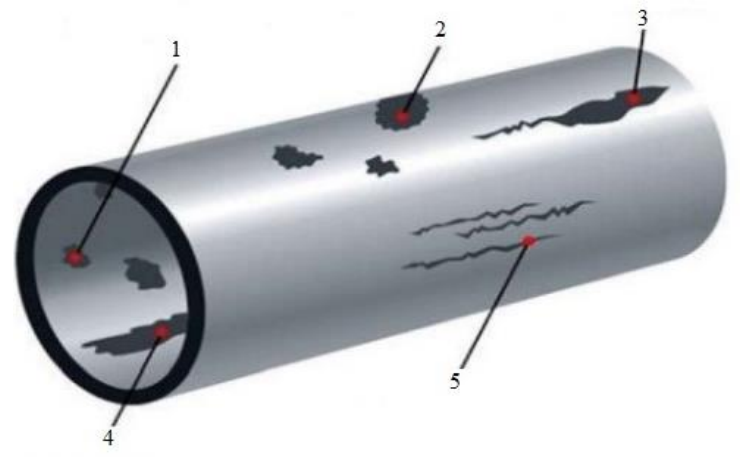

1-internal corrosion: pitting or uniform corrosion.

2-exrenal corrosion: MIC, oxidation, under deposition.

3- hydrogen imduced cracking.

4-flow induced corrosion.

5-cracking: stress corrosion cracking, embrittlement, suulfide corrosion cracking.

Fig.3. Corrosion process.

The sensor-based on ultrasonic waves for constant monitoring of the thickness of the pipe determines the corrosion/erosion rates [12]. Based on these data, the intervals for preventive maintenance are calculated, and justified decisions about operation or change of pipes are worked out. These sensors are part of the CPS, in which data over a wireless link is transmitted to processing levels and analytics.

\section{Reliability of mechanical systems}

OGC is a complex technical system, in three sectors of which mechanical equipment is used at all stages of production, for example, rotating mechanisms: asynchronous motors, compressors, pumps, etc. The surveillance of their states and the early detection of hazards allow predicting the development of emergency situations and preventing the risks of losses (financial, environmental and human). At present, the most informative indication of the technical state of mechanical equipment is the analysis of the parameters of the vibration signal. To solve various levels of practical and research problems, the following are used:

- analysis of noise of mechanisms;

- measurement of the overall level of vibration;

- measurement of vibration parameters;

- analysis of the vibrational signal spectrum and analysis of temporal realizations.

The investigation of vibration parameters and prediction of incipient defects of machines and mechanisms on its basis is a common practice. We shall confine ourselves to the reduction of some sources in this field [13-15].

\section{Environmental monitoring and safe operatio.}

One of the important analytical tasks in the performance of drilling operations is to prevent the risk of opening the gas pockets and the flow of oil. To achieve these goals, periodic monitoring and measurement of the content of gases in the drilling fluid are carried out in the process of drilling operations. These include ammonia
(NH3), hydrogen sulfide (H2S) and sulfur dioxide (SO2) [16]. The emission of those in the environment can lead to an ecological imbalance and an exposure of the human to those can cause dizziness, headaches and even death. For example, $\mathrm{H} 2 \mathrm{~S}$ is one of the leading causes of death in the workplace in the US and, according to the Bureau of Labor Statistics, H2S caused 60 deaths among workers between 2001 and 2010 [17]. The risks of explosions of flammable gases are very high. Thus, the monitoring of emissions and the chemical composition of gases and toxic substances by sensors is an important aspect of environmental monitoring and safe operation at all stages of production processes.

The statistical data given in Table 1 show the consequences of accidents during work at OGC facilities $[18,19]$.

Table 1. Incidents occurred in oil facilities

\begin{tabular}{|c|c|c|c|}
\hline No & Facility & Cause of accident & Loses \\
\hline 1 & $\begin{array}{l}\text { Ekofisk, Norway } \\
\text { (1975) }\end{array}$ & $\begin{array}{l}\text { Blowout and oil } \\
\text { riser failure resulted } \\
\text { in a major fire }\end{array}$ & 6 dead \\
\hline 2 & $\begin{array}{l}\text { Piper Alpha, North } \\
\text { Sea, UK(1978) }\end{array}$ & $\begin{array}{c}\text { Gas leak arising } \\
\text { from valve } \\
\text { problems resulted in } \\
\text { explosion }\end{array}$ & $\begin{array}{l}167 \text { dead, } \\
\$ 3 \text { bln. } \\
\text { loss }\end{array}$ \\
\hline 3 & $\begin{array}{l}\text { Mobil Oil Rig, } \\
\text { Nigeria (1995) }\end{array}$ & Explosion of oil rig & 13 dead \\
\hline 4 & $\begin{array}{c}\text { Esso, Longford, } \\
\text { Victoria, Australia } \\
(1998)\end{array}$ & $\begin{array}{l}\text { Human error in gas } \\
\text { production plant }\end{array}$ & $\begin{array}{l}2 \text { dead, } \\
\$ 1.3 \text { bln. } \\
\text { loss }\end{array}$ \\
\hline 5 & $\begin{array}{l}\text { Glomar, Arctic IV, } \\
\text { Invergordon (1998) }\end{array}$ & Explosion in rig & 2 dead \\
\hline 6 & Petrobras (2001) & $\begin{array}{l}\text { Explosion in } \\
\text { platform }\end{array}$ & $\begin{array}{l}10 \text { dead, } \\
\$ 430 \\
\text { bln. loss }\end{array}$ \\
\hline 7 & $\begin{array}{c}\text { Deepwater Horizon } \\
(2010)\end{array}$ & Explosion & 11 dead \\
\hline 8 & $\begin{array}{l}\text { Gulf of Mexico } \\
(2015)\end{array}$ & Explosion & 4 dead \\
\hline
\end{tabular}

Summarizing the above-mentioned studies and analysis of the latest advancements in the information technology, in particular, IoT, it can be assumed that, the most advanced results of efficient and reliable OGC functioning in the framework of modern trends are possible when considering OGC's as CPS. That is, it is necessary to maintain the optimal performance of its physical and cybernetic essence:

- Production-technological assets (wells, pumps, compressors, pipelines, processing of raw materials, etc.);

- Information technology assets (sensors, as information sources, computing devices, storage devices, telecommunications equipment and related software).

This can be achieved through optimal selection, implementation and maintenance. The demand for the maintenance at OGC facilities can be judged by the number of equipment failures on the offshore oil and gas platform (Table 2) [21]. 
Table 2. The frequency of rejections on offshore

\begin{tabular}{|c|c|c|}
\hline No & Elements & $\begin{array}{c}\text { Failure } \\
\text { frequency } \\
\text { per year }\end{array}$ \\
\hline 1 & Flow control valve failure & 0.0250 \\
\hline 2 & Level indicator failure & 0.0200 \\
\hline 3 & Impurities causing exothermic reaction & 0.0030 \\
\hline 4 & Safety valve undersize, failure & 0.0500 \\
\hline 5 & Gas pipeline or valve choked & 0.0015 \\
\hline 6 & Temperature controller failed & 0.0200 \\
\hline 7 & Pressure controller system failed & 0.0200 \\
\hline 8 & Leak from compressor downstream pipeline & 0.0065 \\
\hline 9 & Leaking of seal in compressor & 0.1200 \\
\hline 10 & Pump failed to operate and caused release of & 0.1500 \\
\hline
\end{tabular}

The principles of organization and the main known maintenance strategies are detailed in several studies and standards [21-23]:

Reactive Maintenance. It is always used when the deterioration of the object causes a functional failure. The basis of this strategy is the principle of quick troubleshooting without studying the root causes of their occurrence.

Preventive Maintenance. Based on the assumption that there is a causal relationship between scheduled maintenance and operational reliability. It is assumed that the statistics on the failure rates $\lambda(t)$ accumulated as a result of operation allows us to accurately calculate the reliability and determine the time interval $\Delta t$, after which it is necessary to repair the equipment.

Proactive Maintenance. It is implemented as a systematic identification and elimination of pre-existing situations (potential failures) that can create unstable working conditions.

Predictive Maintenance or Condition Based Maintenance (CBM), Condition Monitoring Maintenance. It presupposes the monitoring and diagnosis of the real state of the equipment with the help of measuring equipment and further, a forecast is made about the expediency of future preventive or repair work on the basis of the mathematical apparatus without allowing a functional failure of the equipment.

Reliability Centered Maintenance (RCM). It is implemented on the basis of assessments of the consequences of failures and the functional importance of the components of the system, that is, the emphasis is on ensuring the reliability of units or equipment critical for the operation of the system. In this strategy, failure refers to any unsatisfactory state of the system when either a loss of performance occurs (the system stops working) or loss of acceptable quality (work continues, but ergometric parameters deteriorate).

Risk-Based Maintenance (RBM). RBM provides the strategy of maintenance responsibility for the minimization of risks due to likely unforeseen equipment failures and incessant production effectiveness.

The introduction of CPS and IoT technologies presents new technological opportunities that dramatically change how the production equipment and the need for conducting maintenance works are monitored.

Ref. [24] provides examples of various methods for the monitoring of OGC processes alongside the rationale for using CBM technology. In [25-27], various aspects of the application of CBM technology are analyzed.

As noted above, the functioning of the CPS is carried out by the integration of its two subsystems: productiontechnology and information technology. In the context of fulfilling its production tasks, it is necessary to ensure the reliability of critical technological processes in order to minimize various kinds of damage. To solve this problem the most acceptable is the maintenance strategies of RCM and RBM [28].

In fact, $\mathrm{RCM}$ and $\mathrm{RBM}$ prescribe the use of monitoring, maintenance and repair of equipment for both managing and preventing defects/failures in their operation, and for optimizing operating modes in order to minimize possible negative consequences. For this purpose, Failure Mode and Effects Analysis (FMEA) and Fault Tree Analysis (FTA) are used as tools [29].

The essence of the FMEA method is to identify and analyze likely defects or failures, their possible consequences, and to develop recommendations and actions to eliminate these causes and prevent or prevent possible consequences.

Using Boolean algebra methods, a logical diagram is constructed in FTA that combines low-level failures leading to the failure of the entire system. The fundamental concept of the FTA consists of the translation of the physical system in a structuralized logical diagram in which certain specific reasons lead to an interesting event.

\section{RELATED WORKS}

The analysis of published sources shows that in the present time modern technologies machine-to-machine (M2M), wireless sensor networks (WSN), IoT and industrial IoT (IIoT) have become widely used in OGC [30-32]. The automation systems use sensors in oil fields to collect data and monitor the operation of equipment in real time. For example, one drilling rig in an oil field can generate terabytes of data a day, however, only a small part of it is used to make decisions. According to the estimations of McKinsey experts, a typical offshore production platform may have more than 40,000 metadata, although many of them may not be used, i.e., opportunities that could be obtained from the appropriate use of data and technology are not fully used [33]. Not all data are analyzed to predict potential equipment problems. Since, oil and gas operations become more complicated and remote; the state of equipment often becomes difficult to see especially on remote offshore platforms or in deep-water areas. The lack of visibility may lead to costly unplanned maintenance or to oil leaks during the accidents caused by equipment failure. Even slight improvements in efficiency can provide significant savings. Technically sound, timely and immediate solutions to these problems can be considered as important factors that affect the development of the OGC. 
With the use of modern information technologies, this direction is constantly developing to increase the speed of exploration and detection of oil, increase oil production and reduce the risks to health, security of humans and the environment identified as a result of equipment malfunctions or operator errors. Application of IoT, which is based on sensors, can be taken as a topical choice on the way of implementing the right strategy in gathering information in the OGC. IoT [34] is a new technology with sensors, computing capabilities, memory and built-in short-range transceivers, which provides a new form of communication between people and things, as well as among things themselves. This evolution is the basis of the structure of modern CPS. CPS consists of numerous components, including those that are different from the functional applications of IoT, controlled by computer algorithms, closely integrated with the Internet and users [35, 36]. These include systems such as Smart Cities, Smart Grids, Smart Factory, Smart Buildings, Smart Houses and Smart Cars, where each object is connected to all others. This should ensure adaptive, flexible and cost-effective operation. Concretely, the production systems in a CPS-enabled smart factory will be able to react in real-time to changes on the market and in the supply chain adjusting the flow of goods autonomously [37]. As a result, the entire production chain will be optimized to an extent that is beyond imagination today. CPS is enabling companies to offer remote services beyond their traditional competencies. These services can take various forms but are likely to revolve around a few key themes: predictive and prescriptive analytics, remote access, and remote monitoring. Predictive and prescriptive analytics make sense of raw data that otherwise would have little value. With techniques such as statistics, modeling, data mining, and machine learning predictive analytics is key to making predictions notably on the maintenance of machines or on resource efficiency.

It can be assumed that the OGC is an informationprocessing factory to some extent that fits into the information technology concept of the CPS. It is a large number of devices with built-in sensors, processors and storage media.

IIoT is a type of IoT for corporate/industrial use is a system of integrated computer networks and connected industrial facilities with built-in sensors and software for data collection and exchange with the opportunity of automated remote control and management without human intervention. The following features characterize the application of IIoT:

- Generation of big data streams;

- Multilevel data storage;

- Real-time processing;

- Big Data Analytics;

- Forecasting;

- Control and management.

These IIoT capabilities open up new prospects for solving problems in OGC classified by the International
Society of Automation (ISA) as components of industrial systems [38]:

- Safety/Emergency.

- Close loop regulatory control.

- Close loop supervisory.

- Open loop control.

- Alerting.

- Information gathering.

- Prolonged and reliable operation in case of intensive exposure to the environment.

The effective development and implementation of IIoT will depend on the accelerated transition to the Internet protocol version 6 (IPv6). IPv6 removes restrictions on the address space and allows you to have a unique IP address for each sensor, node or device.

However, there are problems associated with some aspects of implementing IPv6, which include security management, the implementation of interfaces that support the dual IPv6 and IPv4 environment and the adoption of new standards.

The development of IIoT technology is related WSN. Identification of anomalies for monitoring and management in the OGC constitutes the systems based on WSN and SCADA. Each of them has certain limitations. These systems are expensive and inflexible, difficult to scale and have many problems related to data collection, transmission and processing.

\section{Proposed Model of OGC}

Traditionally, information flows' processing and management in OGC producing enterprises occur on three levels. At the lower level, data monitoring, data collection from sensors and primary processing of information for the purpose of developing control actions on oil and gas production facilities is carried out in real time with the help of local-group devices. Replacement of conservative and mostly manual control and monitoring devices and the provision of production, transportation and processing processes in the OGC with new, easy-toinstall sensors allows for continuous automatic control of technological processes, registration and storage of data, and remote configuration. Thus, it is possible to increase reliability, security, energy efficiency and influence on environmental indicators, such as gas emissions, leaks and spills of primary raw materials. At the next level, decisions are made on optimizing processes, determining the frequency of repair activities to reduce downtime and optimizing maintenance intervals for units and assemblies, ensuring efficient operation, etc. Unplanned downtime due to equipment breakdowns that lead to loss of time and finances can be reduced through the introduction of intelligent maintenance systems. The third level is the level of the company on which the analysis is implemented, which results in the coordination of activities that are part of the company (cloud) of enterprises and structures to achieve overall efficiency, measures are taken to increase security and reduce risks 
[39]. This classic model has become a deterrent factor with the development of information technologies, including IoT, whereas the number of both sensors and devices interacting via the Internet has begun to grow rapidly. Sending all the data to the top level (cloud) requires unreasonably high network bandwidth. However, in many critical structures, such as OGC, signal delays between sensors and devices are critical, which, in turn, affects the efficiency of control [40].

The proposed model based on the M2M, WSN, IoT, IIoT technologies, another level is added to OGC information system - fog computing to cope with the growing number of IoT devices and, accordingly, with the network load. The most important difference between cloud computing and fog computing is that data is not collected and analyzed in a centralized environment, such as the Data Center, but in the location where data flows are generated in real time. Fog computing is designed to expand cloud storage, computing, and networking functions, thus solving the main problems encountered in the organization of IoT.

The proposed implementation of NGC as CFS is a four-level architecture based on IoT (Fig. 4):

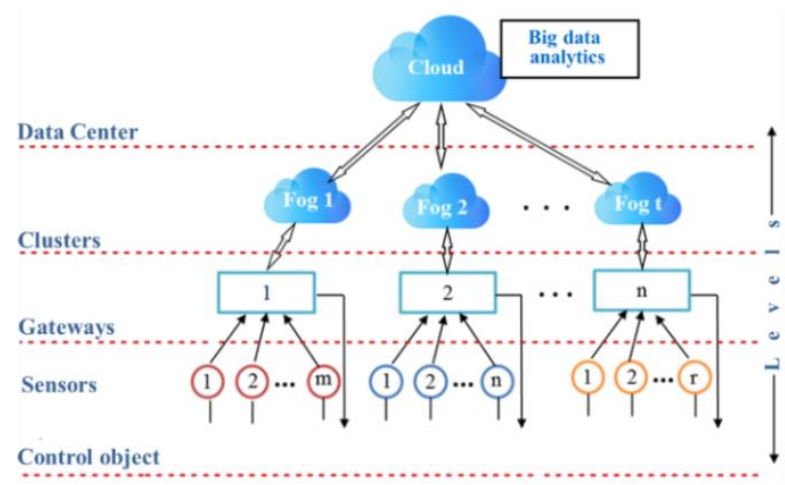

Fig.4. A concept model based CPS on IoT.

As seen from Fig. 4, the basis of CPS is constituted by the physical level, where the large data flow is generated. The main stages of technological processes are spatiallydistributed. They are grouped into clusters according to certain features; data is processed in clusters without the need to transfer to the cloud [41]. Thus, there is a redistribution of the load from the cloud service to fog computing. To increase the reliability and efficiency of management in case of failures or channel congestion, virtual cross-links are created between the corresponding nodes: gateway-gateway, gateway-fog and fog-fog.

The functions of each level are reviewed below:

Sensors - at this level objects in the system are equipped with sensors, with which physical quantities [42-45], such as acceleration, displacement, temperature, pressure, etc., are converted, as a rule, to an electrical signal. The information represented by an electrical signal can conveniently be converted to a digital binary code, automatically registered and transmitted over a distance, processed by mathematical methods and algorithms and stored for a long time in computer systems (personal computers, data centers). Some typical sensors and the parameters measured by them shows in Fig. 5 [46].

A modern trend in sensory technologies is the use of active measurement principles to increase selectivity, sensitivity, stability (for example, sensory elements on the Hall or Coriolis effect), as well as representing selfdiagnosis and self-calibration capabilities.

A promising area is fiber-optic sensors based on Fiber Bragg Grating (FBG) [47]. Sensors based on FBG are especially attractive as pressure sensors and in long arrays with a multitude of temperature measurement points (eg, pipelines). They provide more reliable data, can operate under difficult operating conditions of the equipment and transmit data for distances of several tens of kilometers.

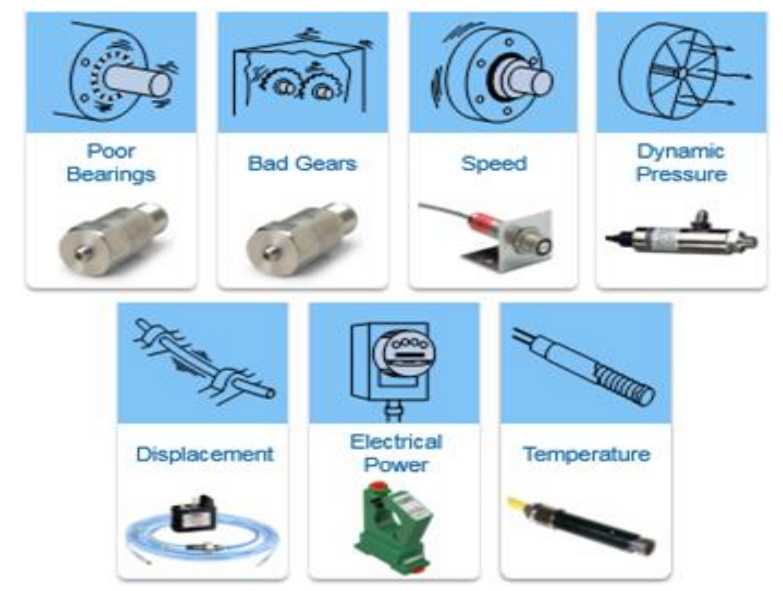

Fig.5. Typical sensors.

By analogy with industry, the development of sensory technology also distinguishes four stages of evolution (Fig. 6) [48]:

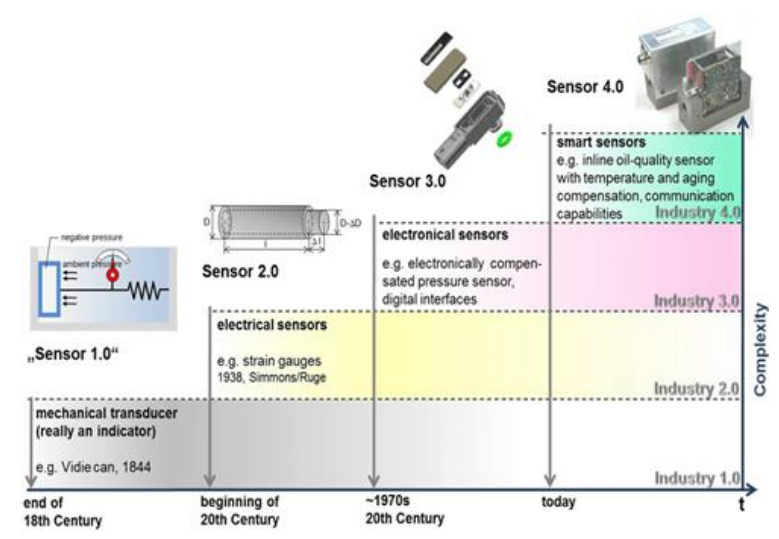

Fig.6. Historic evolution from "Sensor 1.0" to "Sensor 4.0".

1. Sensor 1.0 - mechanical indicators;

2. Sensor 2.0 -electrical sensors;

3. Sensor 3.0 - electronic sensors;

4. Sensor 4.0 - intelligent or "smart" sensors.

Consider the properties and capabilities of an intelligent sensor. The intelligent sensor comprises a measuring device, a calculating unit that analyzes the measurement results, and a communication unit for 
transferring the digital information to a large system or cloud via sensor networks. In order to represent phenomena accurately, the signal passes through various stages of amplification or filtration (Fig. 7) [49].

However, the further transmission of the electrical signal through the communication channels in the analog form has a number of disadvantages, the main ones of which are low noise immunity and energy efficiency. To represent the original information in the form of data suitable for processing, storage and transmission in digital format, an analog-to-digital conversion procedure is necessary Data is usually stored on the local server and then sent to the data center. To connect sensors and other systems to the Internet, wired and wireless connections are used, for example, 2G / 3G / 4G, Wi-Fi, ZigBee, Bluetooth, WiMAX, RFID, 6LoWPAN [50]. To date, the application of WSN with obvious advantages is topical. WSN for use in OGC should have the following properties [51]:

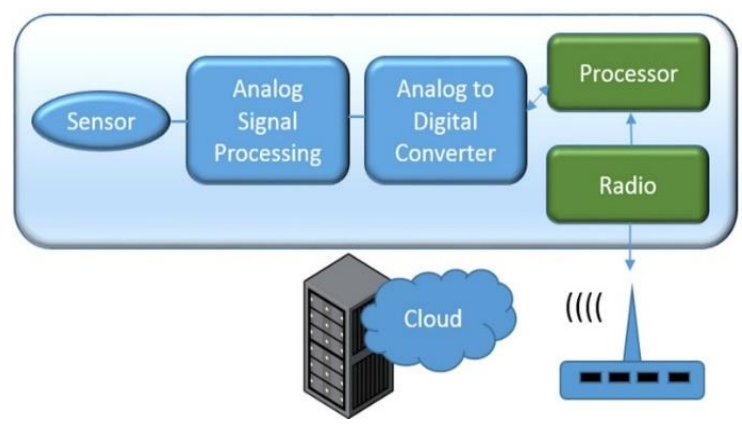

Fig.7. Block-scheme of the intelligent sensor.

- Restricted size, shape, construction and certification.

- Make do with limited processing power, memory, storage, battery consumption and screen real estate.

- Self-contained. When possible, devices should generate their own power or, contain battery packs with an extended battery life of many years to reduce maintenance requirements.

- Operate in a difficult wireless environment in terms of both radio noise and obstructions but also where certain restrictions on such radio devices are present (such as flammable areas).

- Operate in hostile areas where environmental and platform conditions may be very harsh.

- Seamlessly integrate with existing IT solutions.

- Self-reconfigurable, dynamic and adaptive.

- Embedded platforms. Implement complex network algorithms with real-time requirements and adaptive routing protocols et al.

Gateways - the level of preprocessing of data and communications. It is a transport hub between the physical world and cyberspace. At this level, the data is processed in real time and, if necessary, transported to the upper level.

Clusters - fog applications and detection of anomalies. At this level, comparing new data with reference data or previously created baseline states, or using stateful monitoring using data modeling, it is determined to which cluster the current state of the asset is assigned to. For instance, in the oil field, local monitoring and control of oil pumps of various modifications are performed based on the sensed data. Data is also transferred to the fog, where it is processed by the applications for the purpose of coordinating the impact on the operation modes of individual wells in order to achieve economic efficiency. The fog stores all the necessary optimization criteria used when finding the extremum of the objective function. Equipment downtime, costs of electricity, steam, water, as well as the optimization of the entire production process are reduced due to the introduction of this intelligent system.

Data Center - the level of forecasting and analytics (Big Data analytics). Based on the diagnostic data, a predictive estimate is given to determine the inevitable time-base failures. The service is carried out on the basis of specific information about the equipment, which is a reliable predecessor of the inevitable failure. Information is also provided on what actions should be taken to optimize the life cycle of the asset or increase productivity in the enterprise by reducing the downtime of equipment or process [52].

CPS stores and maintains data in the cloud using standard formats. The use of standard formats allows developers to create interactive web applications and mobile applications to provide information to users at different levels of OGC. For example, a business analyst needs information about bandwidth, productivity, supply chain management, and so on during an international flight. Alternatively, the engineer must see the life-cycle management information and product quality assessments through the web interface within the company.

\section{CONCLUSION}

At present, OGC is facing new production problems, especially against the backdrop of volatile oil prices. The conducted research shows that the use of modern information means in this direction is constantly developing. The level of technology development in this area opens up new opportunities for enhancing the effective, competitive and safe operation of OGC. In this paper, a concrete study was presented, namely, the smart functioning of OGC as a complex CPS, which was taken by their roots from mergers between computational and physical components of systems. This article discussed emerging issues related to the use of CPS in the OGC. It was shown that the potential of CPS from the implementation at oil production facilities would increase the reliability of the applied practices with the use of more intelligent services. The ease of use of CPS and IoT extends the potential for monitoring the status and management of the main processes of the OGC sectors with more efficient and reliable results. The processing of large data collected using IoT can be performed using cloud computing, Big Data and data mining, and the results will provide operational and predictive control. 


\section{ACKNOWLEDGMENTS}

This work was supported by the Science Development Foundation under the SOCAR - Grant № 01 LR ANAS.

\section{REFERENCES}

[1] M. Brettel, N. Friederichsen, M. Keller, and M. Rosenberg, "How Virtualization, Decentralization and Network Building Change the Manufacturing Landscape: An Industry 4.0 Perspective", International Journal of Information and Communication Engineering, Vol. 8, No. 1, pp. 37-44, 2014.

[2] A. Gilchrist, "Industry 4.0. The Industrial Internet of Things", Apress, p. 250, 2016.

[3] S. Pfeiffer, "The vision of "Industrie 4.0" in the making a case of future told, tamed, and traded", NanoEthics, Vol. 11, No. 1, pp. 107-121, 2017.

[4] H. Kagermann et al. "Recommendations for implementing the strategic initiative INDUSTRIE 4.0: Securing the future of German manufacturing industry"; Final report of the Industrie 4.0 Working Group, p. 79, 2013. https://www.din.de/blob/76902/e8cac883f42bf28536e7e8 $165993 \mathrm{f} 1 \mathrm{fd} / \mathrm{recommendations-for-implementing-industry-}$ 4-0-data.pdf

[5] L. Wang, G. Wang,"Big Data in Cyber-Physical Systems, Digital Manufacturing and Industry 4.0", International Journal of Engineering and Manufacturing (IJEM), Vol.6, No.4, pp.1-8, 2016. DOI: 10.5815/ijem.2016.04.01

[6] I. Dumitrache, I.S. Sacala, M.A. Moisescu, S.I. Caramina, "A conceptual framework for modeling and design of Cyber-Physical Systems", Studies in Informatics and Control, Vol. 26, No. 3, pp. 325-334, 2017.

[7] J Zhao, F Wen, Y Xue, X Li, Z Dong, Cyber physical power systems: Architecture, implementation techniques and challenges, Automation of Electric Power Systems, vol.34, Issue 16, pp. 1-7, 2010.

[8] W. Aldred et al, "Drilling Automation", Oilfield Review, Vol. 24, No. 2, pp. 18-27, 2012.

[9] "Sensors and Switches in Oil Rig Applications", https://sensing.honeywell.com/honeywell-sensorsswitches-oil-rig-application-note-000756-4-en.pdf

[10] M. Karami, "Review of Corrosion Role in Gas Pipeline and Some Methods for Preventing It", J-1 of Pressure Vessel Technology, Vol. 134, pp. 1-5, October 2012.

[11] C. Gómez, D.R. Green, "Small unmanned airborne systems to support oil and gas pipeline monitoring and mapping", Arab J-1 Geosci, Vol. 10, No. 9, pp. 202-219, 2017.

[12] J. Davies, "Ultrasonic Sensor Technology and its Application in the Oil \& Gas Sector", 2015, https://www.sensorsmag.com/components/ultrasonicsensor-technology-and-its-application-oil-gas-sector

[13] A. Muszynska, "Vibrational Diagnostics of Rotating Machinery Malfunctions", International Journal of Rotating Machinery, Vol. 1, No. 3-4, pp. 237-266, 1995.

[14] A. Khadersab, S. Shivakumar, "Vibration Analysis Techniques for Rotating Machinery and its effect on Bearing Faults", Procedia Manufacturing, Vol. 20, pp. 247-252, 2018.

[15] I. Abu-Mahfouz, "Drilling wear detection and classification using vibration signals and artificial neural network", International Journal of Machine Tools \& Manufacture, Vol. 43, pp. 707-720, 2003.
[16] "Oil and Gas Industry - Safety Monitoring. Flame, Toxic/LEL Gas, Ultrasonic, and Particle Detection," http://www.emerson.com/documents/automation/applicati on-note-oil-gas-industry-safety-monitoring-en-72588.pdf

[17] "Oil and gas H2S meters", https://sensorcon-sensingproducts-by-molex.myshopify.com/pages/oilgas

[18] P. Duddu, "The world's worst offshore oil rig disasters", https://www.offshore-technology.com/features/featurethe-worlds-deadliest-offshore-oil-rig-disasters-4149812/

[19] "Major Offshore. Accidents of the 20th \& 21st Century," https://www.arnolditkin.com/oil-rig-explosions/major-oilrig-disasters/

[20] S. Natarajana, R. Srinivasana, "Multi-model based process condition monitoring of offshore oil and gas production process", Journal Chemical engineering research and design, Vol. 88, pp. 572-591, 2010.

[21] "BS 8210: 2012 Guide to facilities maintenance management", http://www.safetymanagementuk.com/wp-content/uploads/2018/04/BS8210-2012-3.pdf

[22] "DIN 31051 Fundamentals of maintenance", https://standards.globalspec.com/std/1539923/din-31051

[23] Sh. Mostafa, et al, "Lean thinking for a maintenance process", Production and Manufacturing Research, Vol. 3, No. 1, pp. 236-272, 2015.

[24] S. Telford, M.I. Mazhar, and I. Howard, "Condition Based Maintenance (CBM) in the Oil and Gas Industry: An Overview of Methods and Techniques", International Conference on Industrial Engineering and Operations Management, Malaysia, pp. 1152-1159, 2011.

[25] S. Selcuk, "Predictive maintenance, its implementation and latest trends", Journal of Engineering Manufacture, Vol. 231, Issue 9, pp. 1670-1679, 2016.

[26] G. Niu, M. Pecht, "A framework for cost-effective and accurate maintenance combining CBM RCM and data fusion", 8th International Conference on Reliability, Maintainability and Safety, ICRMS 2009, pp. 605-611, 2009.

[27] A. Reidt, S. Schuhbäck, and H. Krcmar, "Comprehensive View on Architectural Requirements for Maintenance Information Systems", 13th International Conference on Evaluation of Novel Approaches to Software Engineering, pp. 249-257, 2018.

[28] "Reliability centered maintenance. Guide for facilities and collateral equipment", NASA, p. 348, 2000.

[29] R. de Queiroz Souza, A.J. Alvares, "FMEA and FTA Analysis for Application of the Reliability Centered Maintenance Methodology: Case Study on Hydraulic Turbines", ABCM Symposium Series in Mechatronics, Vol. 3, pp.803-812, 2008

[30] W.Z. Khan et al, "A reliable Internet of Things based architecture for oil and gas industry", Advanced Communication Technology (ICACT), 19th International Conference on. IEEE, pp. 705-710, 2017.

[31] M. reza Akhondi, A. Talevski, S. Carlsen, and S. Petersen, "Applications of wireless sensor networks in the oil, gas and resources industries", 24th IEEE International Conference Advanced Information Networking and Applications (AINA), pp.941-948, 2010.

[32] B. E. McAdams, "Wireless Sensor NetworksApplications in Oil and Gas", 05/2016. http://www.remotemagazine.com/main/articles/wirelesssensor-networks-applications-in-oil-gas/

[33] S. Martinotti, J. Nolten, and J.A. Steinsbo, "Digitizing oil and gas production", 08/2014, https://www.mckinsey.com/industries/oil-and-gas/ourinsights/digitizing-oil-and-gas-production 
[34] "Internet http://literature.cdn.keysight.com/litweb/pdf/59921217EN.pdf

[35] R. Alguliyev, Y. Imamverdiyev, L. Sukhostat, "Cyberphysical systems and their security issues", Computers in Industry, Vol. 100, pp .212-223, 2018.

[36] E.A. Lee, "Cyber physical systems: Design challenges", 11th IEEE international symposium on object oriented real-time distributed computing (ISORC), pp. 363-369, 2008.

[37] L. Probst et al, "Service Innovation for Smart Industry", EU, Luxembourg, 12 p., 2015.

[38] R. Mohsin, et al, "A critical analysis of research potential, challenges, and future directives in industrial wireless sensor networks", IEEE Communications surveys and tutorials, vol.20, issue 1, pp. 39-95, 2018.

[39] R. Alguliyev, T. Fataliyev, Sh. Mehdiyev, "Some issues of application of internet of things in the oil and gas complex", the 6th International Conference on Control and Optimization with Industrial Applications, July 11-13, pp. 46-48, 2018.

[40] M. Chiang, T. Zhang, "Fog and IoT: An overview of research opportunities", IEEE Internet of Things Journal, Vol. 3, No..6, pp. 854-864, 2016.

[41] R. G. Alakbarov, O.R. Alakbarov, "Effective use Method of Cloudlet Resources by Mobile Users", International Journal of Computer Network and Information Security(IJCNIS), Vol.10, No.2, pp.46-52, 2018.

[42] R. Jamal, "Sensors need to evolve to make Industry 4.0 workable", http://www.controlengeurope.com/article/87387/Sensorsneed-to-evolve-to-make-Industry-4-0-workable.aspx

[43] S.J. Oks, A. Fritzsche, and K.M. Möslein, "An Application Map for Industrial Cyber-Physical Systems", Industrial Internet of Things. Cyber manufacturing Systems, Springer Series in Wireless Technology, pp. 2146, 2017.

[44] J. Wilson, "Sensor Technology Handbook", Elsevier, Oxford, p.703, 2005.

[45] R. Bogue, "Sensors for condition monitoring: a review of technologies and applications," Sensor Review, Vol. 33, Issue 4, pp. 295-299, 2013.

[46] "Sensors for condition monitoring", 2016/04/12, http://www.ni.com/white-paper/52461/en/

[47] L.K. Cheng, R.A. Nieuwland, P.M. Toet, and K. Agovic, "Fiber Bragg grating sensors", Symposium IEEE Photonics Benelux Chapter, pp. 149-152, 2010.

[48] A. Schütze, N. Helwig, and T. Schneider, "Sensors $4.0-$ smart sensors and measurement technology enable Industry 4.0", Journal of Sensors and Sensors Systems, No. 7, pp. 359-371, 2018.

[49] G. Lebsack, "Sensors Drive IoT Intelligent Systems", 2018/01/04, https://semiengineering.com/sensors-driveiot-intelligent-systems/

[50] "11 Internet of Things (IoT) Protocols You Need to Know About”, https://www.rs-online.com/designspark/eleveninternet-of-things-iot-protocols-you-need-to-know-about

[51] T. Sobral, "Wireless Sensor Network for Oil and Gas Industry", www.siliconreef.com.br.

[52] E. Jantunen, et al. "Remote maintenance support with the aid of cyber-physical systems and cloud technology", Journal of Systems and Control Engineering, Vol.232 Issue 6, pp.784-794, 2018.

\section{Authors' Profiles}

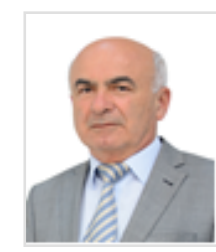

Tahmasib Khanahmad Fataliyev: graduated from Automation and Computer Engineering faculty of Azerbaijan Polytechnic University. His primary research interests include various areas in e-science, data processing and computer networks. He is head of the department at the Institute of Information Technology of ANAS, Azerbaijan. He is the author of about 100 scientific papers.

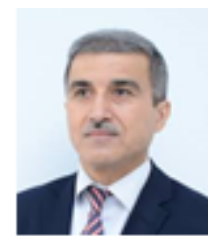

Shakir Agajan Mehdiyev: graduated from Automation and Computer Engineering faculty of Azerbaijan Polytechnic University. His primary research interests include various areas in e-science, computer networks and maintenance. He is head of the department at the Institute of Information Technology of ANAS, Azerbaijan. He is the author of about 20 scientific papers.

How to cite this paper: Tahmasib Kh. Fataliyev, Shakir A Mehdiyev, "Analysis and New Approaches to the Solution of Problems of Operation of Oil and Gas Complex as CyberPhysical System", International Journal of Information Technology and Computer Science(IJITCS), Vol.10, No.11, pp.67-76, 2018. DOI: 10.5815/ijitcs.2018.11.07 